\title{
Raft Formation of Sodium Alginate in the Stomach
}

\author{
Hee Man Kim \\ Division of Gastroenterology and Hepatology, Department of Internal Medicine, Yonsei University Wonju College of Medicine, Wonju, Korea
}

Sodium alginate is used to relieve symptoms of gastroesophageal reflux disease. ${ }^{1}$ When combined with acid, sodium alginate precipitates and forms a gel form. Bicarbonate-containing alginate formulations such as Gaviscon (Reckitt Benckiser Healthcare, Hull,
$\mathrm{UK}$ ) release carbon dioxide as a reaction to gastric acid, and the carbon dioxide is entrapped in the gel precipitate, forming a "raft." On the other hand, an alginate formulation without gas generation forms a "raft" in the stomach, if the dosage form has a lower density
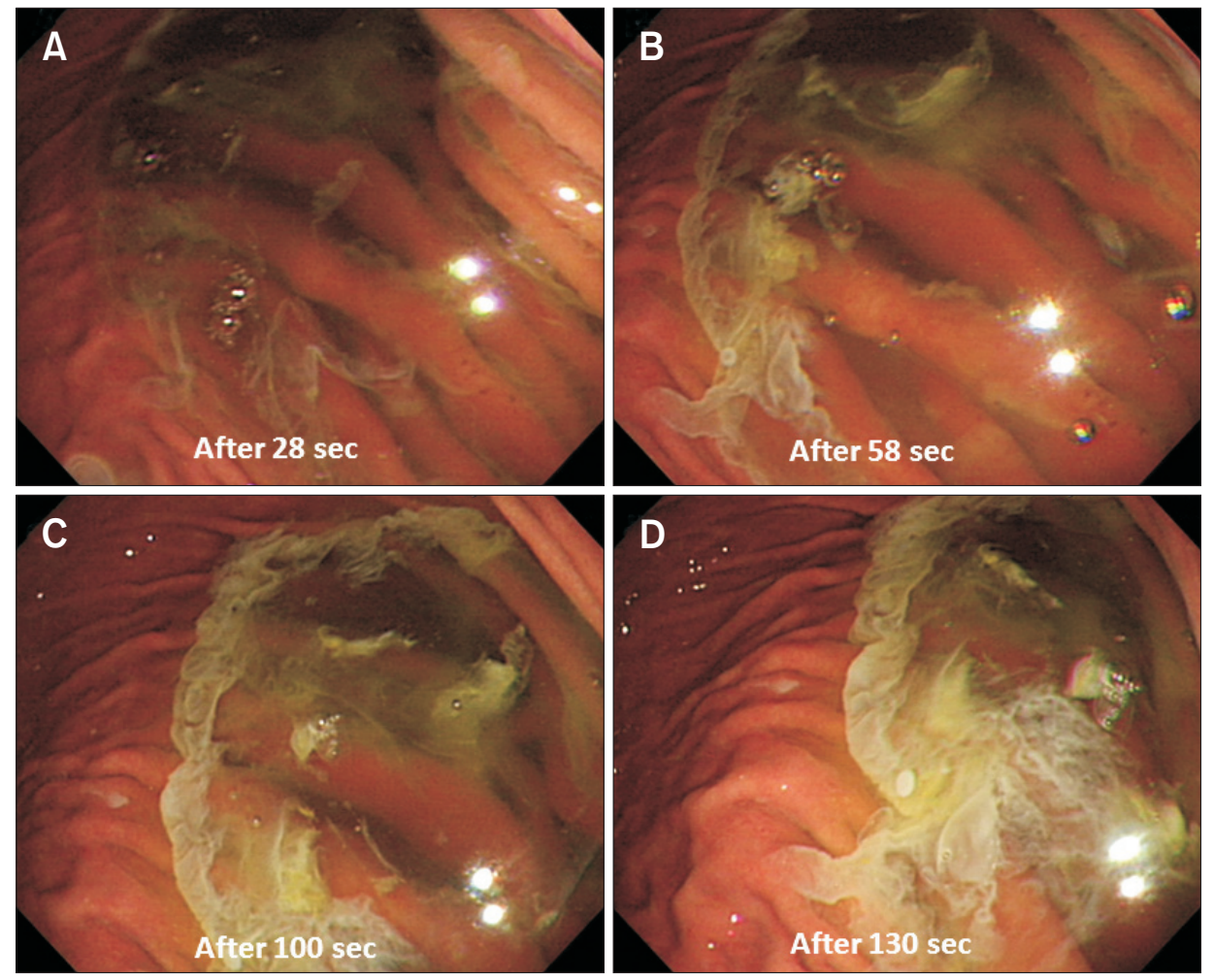

Figure. Raft formation of sodium alginate. (A) After 28 seconds of infusion, a precipitate developed. (B and C) A thin membrane-like material formed at the boundary. (D) The membrane floated on the gastric fluid.

Received: April 19, 2016 Revised:June 14, 2016 Accepted: August 15, 2016

(a) This is an Open Access article distributed under the terms of the Creative Commons Attribution Non-Commercial License (http://creativecommons. org/licenses/by-nc/4.0) which permits unrestricted non-commercial use, distribution, and reproduction in any medium, provided the original work is properly cited.

*Correspondence: Hee Man Kim, MD, PhD

Division of Gastroenterology and Hepatology, Department of Internal Medicine, Yonsei University Wonju College of Medicine, 20 Ilsan-ro, Yonsei University Wonju College of Medicine, Wonju 26426, Korea Tel: +82-33-741-1229, Fax: +82-33-741-1228, E-mail: nicekorea2@gmail.com 
than that of gastric fluid, which is $1.004 \mathrm{~g} / \mathrm{cm}^{3}{ }^{3}$. Herein, pictures of the raft formation observed on esophagogastroduodenoscopy (EGD) are shown.

A 35-year-old woman underwent EGD for chronic dyspepsia. During EGD, a biopsy was performed for a small erosion. Then, to prevent hemorrhage from the biopsy site, alginate (Lamina G, Taejoon Pharm, Korea) was infused into the stomach under EGD. Soon after the infusion of sodium alginate, a precipitate developed on the surface of the gastric fluid (Figure A). Then, a thin membrane-like material formed at the boundary of the gastric fluid (Figure B and C), and the size of the membrane grew, forming a "raft" (Figure D) (Supplementary Video).

Floating drug delivery systems are classified into non-effervescent and effervescent systems. ${ }^{3}$ The non-effervescent system includes matrix-forming polymers such as sodium alginate. ${ }^{4}$ The effervescent system includes gas-generating systems such as Gaviscon and volatile liquid-containing systems. ${ }^{3}$ In this case, the floating phenomenon of alginate precipitate might have resulted from the low density of the non-effervescent system used. Although the alginate "raft" would have sunk after several minutes, it may explain part of the symptom relief experienced shortly after ingestion of sodium alginate only.

\section{Supplementary Material}

Note: To access the supplementary video mentioned in this article, visit the online version of Journal of Neurogastroenterology and Motility at http://www.jnmjournal.org/, and at http://dx.doi. org/10.5056/jnm16068.

\section{Financial support: None.}

Conflicts of interest: None.

\section{References}

1. Mandel KG, Daggy BP, Brodie DA, Jacoby HI. Review article: alginateraft formulations in the treatment of heartburn and acid reflux. Aliment Pharmacol Ther 2000;14:669-690.

2. Kwiatek MA, Roman S, Fareeduddin A, Pandolfino JE, Kahrilas PJ. An alginate-antacid formulation (Gaviscon Double Action Liquid) can eliminate or displace the postprandial "acid pocket" in symptomatic GERD patients. Aliment Pharmacol Ther 2011;34:59-66.

3. Lopes CM, Bettencourt C, Rossi A, Buttini F, Barata P. Overview on gastroretentive drug delivery systems for improving drug bioavailability. Int J Pharm 2016;510:144-158.

4. Singh BN, Kim KH. Floating drug delivery systems: an approach to oral controlled drug delivery via gastric retention. J Control Release 2000;63:235-259. 